\title{
Development and Assessment of a Summer Program to Introduce High School Students to STEM through Aviation and Transportation Engineering
}

\section{Dr. Jalil Kianfar P.E., Saint Louis University, Parks College of Eng.}

Dr. Jalil Kianfar is an assistant professor of civil engineering at Saint Louis University and a registered professional engineer (P.E.) in the state of Missouri. In addition to his academic experience, he has five years of industry experience as a traffic engineer that informs his teaching, research and service. Dr. Kianfar research interests and background includes traffic operations and roadway safety, construction zones and work zone traffic control, and smart cities and connected and autonomous vehicles. Dr. Kianfar also has an interest in engineering education research including blended learning environments, active and collaborative learning, and STEM outreach.

\section{Stephen M Belt, Saint Louis University}

Stephen M. Belt is an assistant professor in the Aviation Science Department at Saint Louis University. $\mathrm{He}$ is a certified flight instructor and commercial pilot. He received a PhD in higher educational administration in 2012 from Saint Louis University. 


\title{
Development and Assessment of a Summer Program to Introduce High School Students to STEM through Aviation and Transportation Engineering
}

\begin{abstract}
This paper describes the curriculum developed for a summer outreach program that used the transportation system to introduce high school students to STEM. The curriculum included modules to introduce participants to the topics of aviation and air transportation, infrastructure design and traffic engineering, inland waterways, transit, and rail transportation. The relationship between safety, design, and operations was described in each module, and the multimodal nature of the transportation system was emphasized. The curriculum included subject-based learning, experiential learning, and out-of-classroom experience. First, students were lectured on the background to and basic knowledge about each mode of transportation. Lectures were followed by a hands-on laboratory class or a computer-based activity where students could apply the basic principles of transportation engineering to solve a problem related to each mode of transportation. Finally, field trips were arranged to help students connect the theory and hands-on activities to real-world engineering and aviation applications. A Likert scale questionnaire was used to inquire about participants' opinions of STEM and to assess the effectiveness of the program in introducing students to STEM. This paper reflects on opportunities and challenges in developing and implementing the curriculum and suggests improvements to it.
\end{abstract}

\section{Introduction}

High school students can relate to travel delays, traffic congestion, the reliability of the transit system, and roadway and aviation safety as they make use of the transportation system almost every day. As such, they can appreciate the effects of transportation infrastructure on the quality of life in a community [1-3]. The planning, design, and maintenance of a transportation system involves various disciplines such as traffic engineering, structural engineering, and hydraulic engineering, and includes modes of transportation such as the automobile, transit, and aviation. The objective of this STEM outreach program was to help its participants to understand how engineers serve the communities they live in, and how engineers work together to apply math and science to solve real-world problems. This paper provides an overview of an outreach program developed at Saint Louis University to serve high school students from the St. Louis region.

\section{Transportation as a Vehicle for Introducing Students to STEM}

Virtually everyone relies on a mode of transportation during their everyday life to access healthcare, commute to work, attend school, or shop. Transportation also plays a significant role in the economic development of regions and is vital to many economic sectors such as 
agriculture, manufacturing, and retail. Providing a safe, sustainable, resilient, equitable, reliable, and efficient transportation system requires a broad and diverse set of expertise that includes civil engineering (infrastructure design and maintenance), computer science and electrical engineering (intelligent transportation system, and autonomous vehicles), mechanical engineering (design of automobiles and other transportation modes), environmental engineering (air quality, and environmental impact assessment) among other science and engineering fields. Given that transportation is universally experienced by K-12 students, and considering the extent to which transportation systems impacts the society and the economy, and the diversity of STEM fields that it includes, a transportation-focused outreach program could be developed to introduce K-12 students to various engineering disciplines and career paths in STEM. In the next section, an overview of the summer program that was developed at Saint Louis University is provided. This program focused on civil engineering and aviation science aspects of transportation system, however, in future the program can be expanded to include other engineering disciplines.

\section{Aviation and Transportation Engineering Outreach Program Outline}

This paper describes a non-residential summer STEM outreach program that was conducted over a five-day period at Saint Louis University. The camp curriculum considered various modes of transportation. One aspect of the transportation system was concentrated on each day, and was referred to as the topic of the day. Modules were developed by a civil engineering or an aviation science faculty. The learning outcomes for each module (topic of the day) were chosen to represent some of the learning outcomes of an introductory college-level course related to the topic of the day. A faculty member delivered the lectures and guided the students in the activities. Two civil engineering graduate students served as academic aides and mentored the students during the hands-on activities. A typical day in the summer program consisted of four primary sessions, and a combination of pedagogical approaches was used to enhance students' learning of materials each day, as follows.

1) Subject-based learning (first morning session). A faculty member delivered a lecture on fundamental concepts of the topic of the day. The purpose of the lecture was to provide students with the background to and basic knowledge on the topic of the day.

2) Experiential learning (second morning session). Students learned about the subject matter through a hands-on laboratory class or a computer-based activity. This direct experience allowed students to apply the basic principles of transportation engineering to solve a problem related to the topic of the day. A faculty member and academic aides assisted students during the activity.

3) Case-based learning (first afternoon session). An experienced transportation professional from the St. Louis area lectured on a recently completed project or a current project relevant to the topic of the day. The purpose was to help students learn the subject matter and related decisionmaking processes through the case study of a real project in the state of Missouri or the greater St. Louis area. A faculty member facilitated a 'question and answer' session between the students and the guest speaker, and helped students to connect what they learned during that morning's lecture and activity with the case study presented by the transportation professional. 
4) Out-of-classroom experience (second afternoon session). Students visited a transportation facility relevant to the topic of the day. This enhanced learning by allowing the students to observe typical activities in a transportation facility, and gave them an opportunity to talk with transportation professionals and learn more about careers in the transportation industry.

The summer program also included modules on coding and presentation skills. The various modules are discussed below.

\section{Summer Program Modules}

The summer program included modules that introduced students to the topics of infrastructure design and traffic engineering, aviation and air transportation, inland waterways, and transit and rail transportation. The relation between safety, design, and operations was described in each module, and the multimodal nature of the transportation system was emphasized. The lectures included examples that connected each day's topic with other STEM-related fields. Figure 1 shows the schedule of the program. A brief description of the learning objectives, hands-on activities, and field trips for each module is presented in this section.

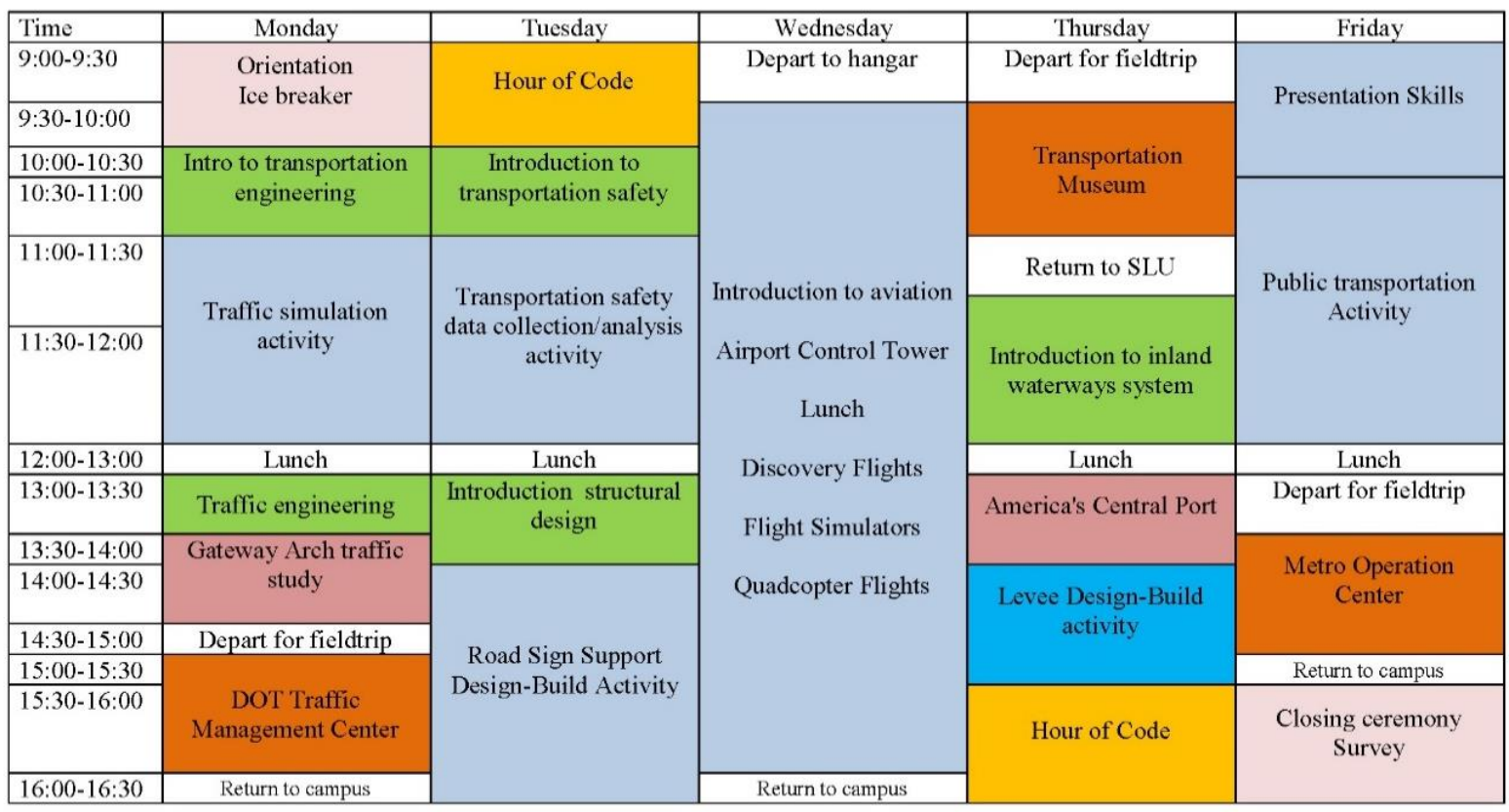

Legend:
\begin{tabular}{|l|}
\hline Orientation/Closing ceremony \\
\hline Lecture \\
\hline Activity \\
\hline Guest Speaker \\
\hline Hour of Code \\
\hline Field Trip \\
\hline
\end{tabular}

Figure 1: Schedule of the Summer Program 
Traffic engineering module. Lecture topics included fundamental traffic diagram, stopping sight distance and geometric design, and the basics of traffic signal control. Students used VISSIM traffic simulation software to analyze the effect of installing a bike lane on vehicular traffic in a street adjacent to the Saint Louis University campus [6]. Students visited the Missouri Department of Transportation's transportation management center (TMC) to learn more about intelligent transportation systems and traffic management. Guest speakers from the Missouri Department of Transportation introduced students to the topic of the design and operation of transportation facilities, and spoke about career options in the transportation industry.

Infrastructure design module. A faculty member introduced students to types of structures and their loading, the stability of structures, and trusses. Students formed teams of three to construct a miniature road sign gantry. The students were provided with limited resources (i.e., tape and pasta) and were asked to design a gantry that would meet minimum design specifications (i.e., clearance and width). Their designs were tested for wind load.

Aviation module. The objective of this module was to familiarize students with the field of aviation. Students learned about aviation from an historical and regulatory perspective. Careers in the aviation field were reviewed, and students were provided with examples of air traffic control procedures and the phraseology used by air traffic controllers. Students visited the Saint Louis University hangar at the St. Louis Downtown Airport and participated in discovery flights.

Inland waterways module. In this module students learned about inland waterways and river transportation. They applied basic principles of hydraulic engineering in a hands-on activity to build and test a levee. A guest speaker from the America's Central introduced the students to port operations, barges, and ferries. Students visited the National Great Rivers Museum and were given a tour of Melvin Price Locks and Dam on the Mississippi River.

Rail and transit module. The last module of the summer program introduced students to public transportation and railway engineering. During the visit to a transit operation center, students attended a lecture session to learn about transit performance measures and operational practices. They also learned about the work of electrical and mechanical engineers in the operation and maintenance of light rail systems. Students visited a transit operations center and observed the on-line train control and signaling systems. They had the opportunity to talk with operators and signal engineers. In a team activity, students worked to develop a transit schedule/map that covered the maximum number of bus stops while meeting the financial constraints of the transit agency.

The summer program also included computer programming and presentation skills development activities. The computer programming activities included sessions of Hour of the Code, the objective of which was to demystify computer programming for students. They worked individually with faculty and academic aides to develop a simple computer program that calculated the cost of transportation of freight. The presentation skills development activity included an introduction to MS PowerPoint and the elements of a good presentation. Students worked in groups of four and prepared presentations of what they had learned during the summer 
program. They delivered their presentations to their peers and parents during the closing ceremony. Figure 2 illustrates students participating in the summer camp activities.
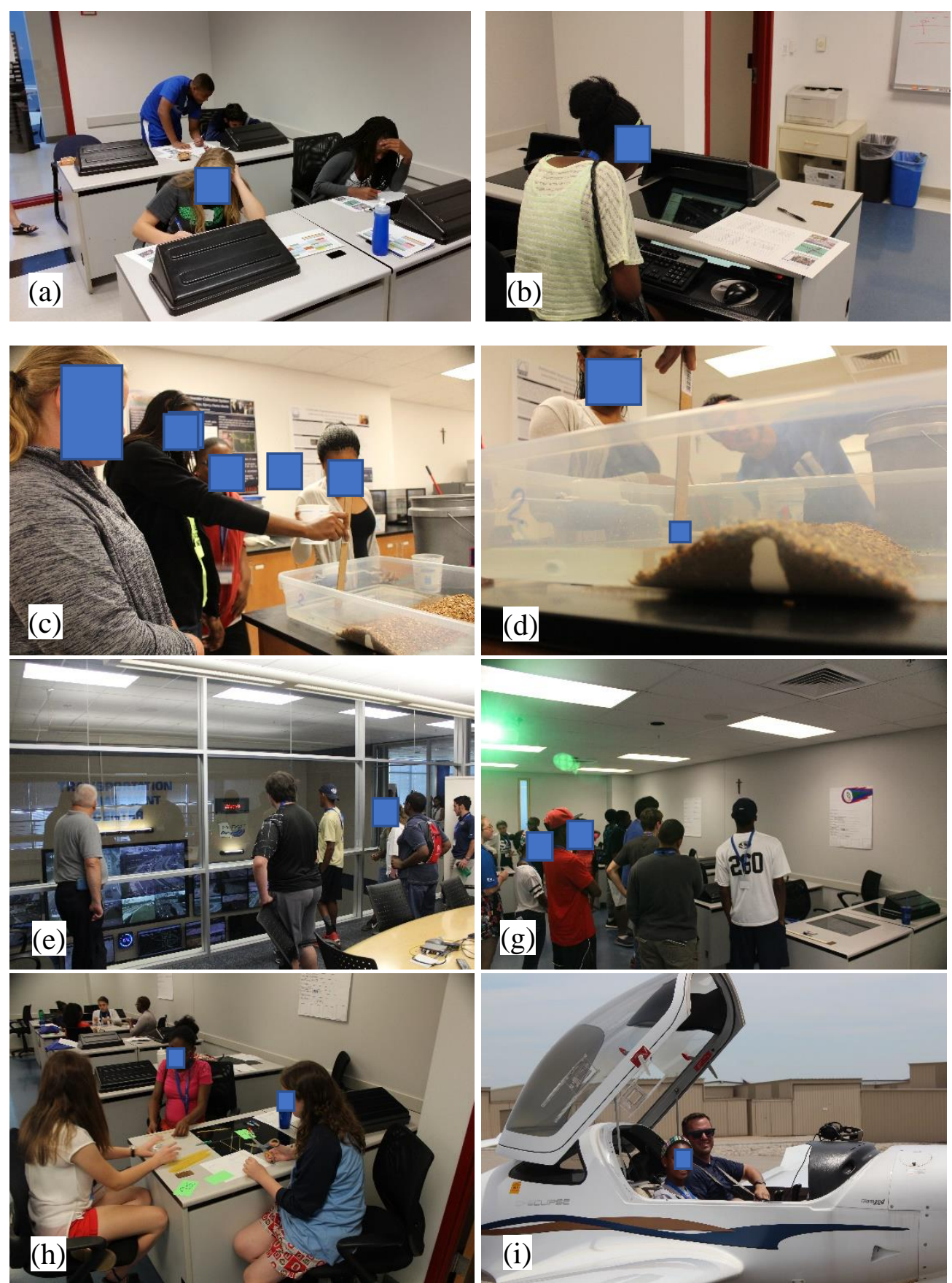

Figure 2. $(a, b)$ Students using a traffic simulation model and comparing the transportation performance measures obtained from various scenarios; $(c, d)$ Students measuring seepage for a levee that they have designed; (e) Students visiting a transportation management center; $(f)$ Students conducting a gallerywalk of the crash report forms developed by their peers; $(g)$ Students designing a roadway sign gantry; (h) A student and a flight instructor about to take off for a discovery flight. 


\section{Implementation of the Summer Program}

The summer program was a non-residential week-long program open to high-school students from St Louis region. The summer program was free to participants and was supported by the Federal Highway Administration National Summer Transportation Institute program. Summer program participants were recruited through social media posts, through summer program booklets produced by Saint Louis University outreach office, and by emailing summer program flyers to high-school counselors in the St. Louis region. Professional engineering societies also assisted in distributing the summer program information. The registration period was between February and May 2017. Thirty-one high-school students applied to the program and were admitted. Thirty students participated in the program, which was held in July 2017. The camp participants were 16 male and 14 female students. Eighteen participants were African-American, 10 were white, one was Asian, and one was Hispanic. Two were rising-sophomore, 20 were rising-juniors, and eight were rising-seniors.

\section{Participants Perspective of the Summer Program}

The summer program was first delivered in 2016 and was repeated in 2017. This paper discusses the perspective of participants in the 2017 summer program. It is worth to mention a survey of participants was not conducted in 2016. On the last day of the summer program, immediately before the closing ceremony, a questionnaire was distributed to the participants to solicit their thoughts about the program curriculum and activities. The questionnaire did not collect any personally identifiable information. Thirty students were enrolled in the program and completed the survey. Upon review of the archival data collected in 2017, the Saint Louis University Institutional Review Board determined that analysis of their answers does not constitute Human Subjects Research. As such, no additional IRB review and approval is needed for this paper.

The questionnaire was in three sections. The first section contained a Likert scale that enquired about the student's opinion of the program, the engineering profession, and attending college. Students stated their opinions on a five-point Likert scale ranging from "strongly disagree" to "strongly agree". The first part of the questionnaire included 11 statements.

- Statement 1: I was able to meet other students with interests similar to mine.

- Statement 2: I was able to design and build projects.

- Statement 3: I was able to learn more about careers in transportation.

- Statement 4: I was able to learn more about engineering.

- Statement 5: I would recommend the [summer program] to other students.

- Statement 6: Before the [summer program], I was interested in majoring in engineering.

- Statement 7: After the [summer program] I would consider majoring in engineering.

- Statement 8: The camp helped me to understand better the importance of college preparatory class work.

- Statement 9: I feel more confident now about making future college and career choices.

- Statement 10: I feel better able to work on a team project.

- Statement 11: I feel more confident that I can handle college courses 
A heatmap of students' responses to these statements is given in Figure 3. It is worth mentioning that a mean and a standard deviation are not the best statistical measures for describing ordinal variables, such as responses to Likert scale survey statements. Stating the percentage of responses to each choice on the Likert scale is the correct approach to describing the survey responses. The Likert scale included responses of "strongly disagree", "disagree", "neutral", "agree", and "strongly agree". The percentages of students' responses to each option are shown in the columns of the Figure 2 heatmap.

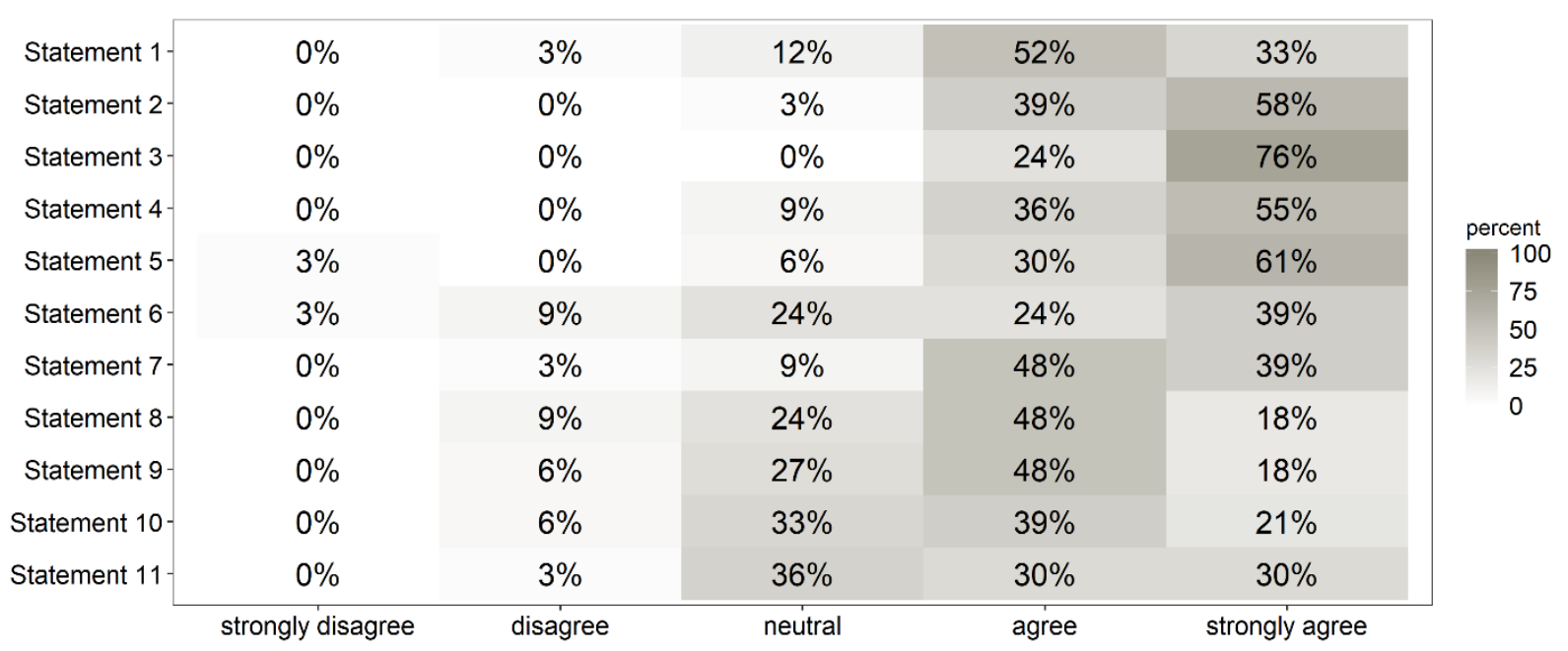

Figure 3: Students' Perspectives on Engineering, Teamwork, and College

Students' responses to statements 8, 7, and 9 indicate that the summer program activities were successful in helping them to understand the importance of college preparatory class work, and increased their interest in pursuing an engineering degree or a college degree. Approximately $6 \%$ of students disagreed with the statement that the summer program activities helped to improve their teamwork skills. This is an area for improvement in future camps, where the faculty and academic aides could conduct daily assessments of teamwork among student groups to identify potential issues, and to intervene and provide guidance to make sure all groups were functional.

The second section of the questionnaire contained a Likert scale that enquired about the guest speakers from industry and the discussion of projects in the St. Louis region. This section contained five questions; they are listed below.

- Statement 1: The speakers aligned with what I expected out of the camp.

- Statement 2: The speakers led me to consider majoring in engineering.

- Statement 3: I learned about the importance of different modes of transportation.

- Statement 4: I understand better how transportation professionals identify and solve problems that impact me in everyday life. 
- Statement 5: Camp presentations and activities helped me to develop my problem-solving skills.

Figure 4 is a diverging stacked bar chart of student responses to statements about guest speakers. The responses to statement 3 indicate that the guest speakers were not effective in motivating students to pursue an engineering degree. However, the guest speakers did effectively communicate the role of transportation professionals in shaping communities.

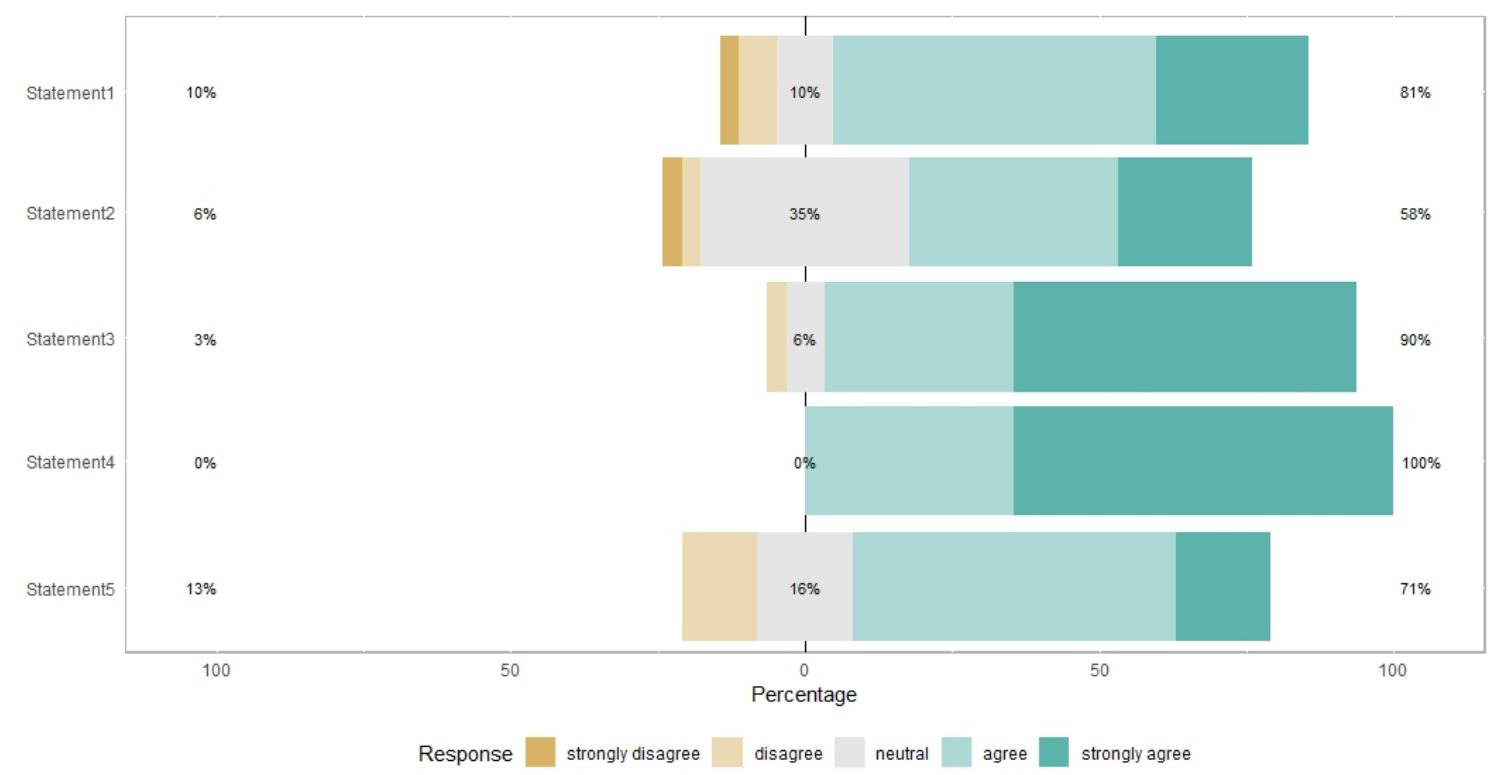

Figure 4: Students' Perspective on Guest Speakers and Transportation Projects in the Community

In the third section of the questionnaire, students were asked, "Please tell us what you think about the [summer program]. What would you say to future students who are considering participation in this camp?" Some of the students' answers to this question are listed below.

- I would say this is a great camp. I will that if you want to explore different types of engineering, this is not the camp. This camp is designed for transportation. This camp did great with giving lectures, activities, and field trips. Everything is balanced, and I had a lot of fun.

- I think that this [camp] was extremely informative about what a traffic engineer actually does and provided a lot of interesting information about how transportation engineers improve travel. Overall, I really enjoyed it. To future students, I would say that this camp is for those who are interested in engineering as a career and are serious about learning about civil/transportation engineering, and Saint University for their futures. This camp could be improved perhaps by limiting the age to 10th grade and above simply because I feel that those students who have been to high school understand better their career options and may get more out of this camp.

- An interesting experience that allows for one to think more interconnectivity about the 
world we live in. Future students should take initiative and respect the opportunity given to them at this camp. Improvements could include less "in-between" time and/or the ability to have a choice in some activities ( 2 or 3 different lectures that occur and a student chooses one or the other).

- It was fun to do the activities. They were hands-on and really got people working together. During the lectures, it might be good to try to add something interactive (like a review game or something) in the middle so the audience will feel more involved. I learned a lot and am happy I came.

- I liked my time here it is fun but there is a lot of listening involved you could make it more hands on the first day.

- I thought the [camp] was a lot of fun. It taught me a lot about engineering. The hands-on activities and field trips gave me a one-of-a kind experience. It was amazing. I would say to future students who are considering to participate in this camp to definitely join and that they won't regret it. One way to improve this camp is by not talking too fast during lectures. Overall, the camp was very fun.

- I enjoyed the opportunity to speak with engineers that chose this profession and ask them why they did so. I would encourage future students to come and hear about what all goes into the structures around us. I would have loved to learn more of the math and physics involved.

- I think that if the lectures were more interactive, people would be much more engaged. Instead of rushing through facts that many of us will forget, slowing down and allowing us to comprehend the information would be much more rewarding for everyone.

Several students did not favor the lecture portions of the program and would have liked more interactive lectures. Few students wished that the program would have included more in-depth math and physics analysis. Several students mentioned that the program narrowly focuses on transportation infrastructure and did not include other engineering disciplines.

During the closing ceremony, students in groups of four were asked to deliver a 10-minute presentation to reflect on what they had learned during the week. In future offerings of the camp, it is suggested to ask students to deliver a presentation based on a specific day of the camp, so that students do not repeat similar points during the closing ceremony. It would also be helpful to provide students with a journal in which to write a summary and reflection at the end of each day.

\section{Summary and Discussion}

This paper provided an overview of a one-week summer program developed to introduce high school students to STEM by focusing on transportation infrastructure. The program included modules related to traffic engineering, structural engineering, and hydraulic engineering, and covered aviation, inland waterways, transit and automobile modes of transportation.

A questionnaire containing a Likert scale was used to gather students' perspectives on the summer program. The survey results indicated that the summer program was successful in 
changing students' perspectives of the engineering profession. Approximately $36 \%$ of participants indicated that they "strongly disagree", "disagree", or have a "neutral" opinion about the statement "Before the [summer program], I was interested in majoring in engineering". After completing the summer program, approximately $12 \%$ of participants indicated that they "disagree" or have a "neutral" opinion about the statement, "After the [summer program] I would consider majoring in engineering." Students indicated that the guest speakers and discussion of local projects helped them to understand the role of engineers in communities. However, the invited speakers were not the most effective in motivating students to consider a career in engineering.

As for future improvements, limiting the summer program to rising 10th and 11th grade students may increase the homogeneity of students to a group more likely to be interested in exploring various career opportunities. Developing activities that focus on geometric roadway design would give students an opportunity to apply geometry, trigonometry, and physics to complete a real-world design problem for a basic roadway curve.

The design and operation of a transportation system includes other engineering disciplines, such as electrical engineering, computer engineering and mechanical engineering. Developing modules related to these engineering disciplines would enable students to learn about a broader range of career opportunities in engineering. However, including additional modules in a weeklong program may limit the time devoted to a meaningful introduction to each discipline.

\section{Acknowledgements}

The summer program was supported by the Federal Highway Administration National Summer Transportation Institute program. Authors would like to thank Elizabeth Reed of Missouri Department of Transportation and Lauren Paulwell of FHWA for their support of the program. Authors would like to thank Dr. Amanda L. Cox, Dr. John Buerck, Dr. Kyle Mitchell, Prof. Stephen Magoc, and Dr. Ronaldo Luna for their contributions to the program.

\section{References}

[1] S. Ivey, M. Golias, P. Palazolo, S. Edwards, and P. Thomas (2012) "Attracting Students to Transportation Engineering," Transp. Res. Rec. J. Transp. Res. Board, vol. 2320, pp. 90-96, Dec. 2012.

[2] C. M. Baker, L. R. Rilett., G. M. Kunz, and G. C. Nugent (2014) "Roads, Rails, and Race Cars: A STEM Educational Program for 4th-12th Grade Students.” ASEE Conferences, Indianapolis, IN.

[3] R. Kommalapati, R. Ramalingam, and W. Stockton (2012) “Transportation Workforce Development: Sustaining and Expanding High School Outreach Programs and Multi-agency Partnerships". Texas A\&M Transportation Institute, UTCM Project \#11-35-69. 
[4] A. Haugh, O. Lang, A. P. Thomas, D. Monson, and D. B. P.E. (2016) "Assessing the Effectiveness of an Engineering Summer Day Camp.” ASEE Conferences, New Orleans, Louisiana.

[5] I. H. Yeter, H. Burley, T. D. Youngblood, and C. M. Williams (2016) "Developing a Questionnaire and Evaluation Methods for a High School Rocket Program.” ASEE Conferences, New Orleans, Louisiana.

[6] Kianfar, J., and Buerck, A. M. (2017). "Bike-lane Traffic Impact Assessment Activity for High School Students (Work in Progress).” American Society for Engineering Education Annual Conference and Exposition. Columbus, OH, June 2017. https://peer.asee.org/27970 